\title{
Pengembangan UKM Online untuk Meningkatkan Kesejahteraan Keluarga Prasejahtera di Makassar
}

\author{
Hasnawiya Hasan*, Rahimuddin, A. Haris Muhammad, Baharuddin \\ Program Studi Teknik Sistem Perkapalan Fakultas Teknik Universitas Hasanuddin* \\ hasnarazak07@gmail.com*
}

\begin{abstract}
Abstrak
LKSA prasejahtera adalah kelompok Ibu-ibu yang memiliki anak berusia balita yang memiliki masalah dengan kebutuhan gizi mereka. Masalah gizi yang dimiliki oleh para balita ini disebabkan keadaan ekonomi orang tua yang buruk. Oleh karena itu, tim pengabdian unhas bertujuan untuk membantu mereka dalam mengembangkan sebuah UKM yang berbasis internet sehingga mereka mampu meningkatkan taraf ekonomi mereka dan membiyai para balita mereka. UKM online sangat cocok untuk kelompok masyarakat ini, sebab tidak membutuhkan modal besar seperti halnya pada model bisnis konvensional. Masyarakat yang menggunakan metode ini, tidak perlu lagi mengeluarkan biaya untuk sewa tempat. Sehingga masyarakat mampu menghemat modal usaha namun tetap memiliki harapan untuk menjangkau jumlah konsumen yang lebih luas. Oleh karena, usaha yang memiliki website mampu mempresentasekan model usahanya dengan lebih detail ke berbagai pihak dan jangkauannya pun tak terbatas. Meski demikian, metode ini membutuhkan keahlian dibidang website devoloper dalam hal merancang website khusus untuk ukm. Ada beberapa tipe website developer yaitu, front end developer,back end developer, dan full-stack developer. Masing-masing web developer tersebut memiliki fungsi dan tugas yang berbeda. Sementara, metode pemograman yang sering digunakan para web developer berupa CMS atau hand-coding. Namun web developer yang bagus akan menggunakan gabungan keduanya $C M S$ dan hand-coding. Sedangkan, bahasa pemograman yang sering digunakan dalam membuat sebuah websites antara lain HTML, CSS, Javascript, PHP, dan Java. Dengan demikian, keluaran dari program pengabdian ini diharapkan berupa kemajuan usaha dengan memanfaatkan website UKM. Sehingga diharapkan masyarakat ekonomi prasejahtera selain mampu meningkatkan pendapatannya juga dapat menjalankan usahanya dengan lebih mudah dan efisien. Selain daripada itu masyarakat diluar kelompok usaha UKM online ini juga dapat meningkatkan efisiensi waktu, tempat, dan biaya dalam menjalankan kehidupan perekonomiannya sehari-hari.
\end{abstract}

Kata Kunci: Websites; UKM-online; front-end; back-end; full-stack.

\begin{abstract}
LKSA prasejahtera is a group of mothers who have todlers with poor phisically growth due to their poor daily nutrition. Those children's problems because of their parents have low income and cannot suport their family. Therefore, the purpose of our program is to help them build an UKM online in order to help them increase their income. This UKM-online is very suitable for their business because of affordable for them compare with the conventional business. These people in the LKSA group do not need rent a place to run their business anymore so they can save more money as we know that the price to rent a strategic place is very high. Howevert, they still can able to run their business and reach more people even they do not have a strategic place. So the website able to help any kind of business because of it provide more detail about their product to many people in unlimeted range. However, this method still needs an expertice in website development in order to build an UKM websites.There are, three type of web developer which are front-end developer, back-end developer,and full-stack developer. Each of web developer has a different function and duty. While, programming language that usually is used in website programming which are, HTML,CSS, Javascript, PHP, and Java. Therefore, the output of this program is expected to be the progress of the business by utilysing an ukm-website. So the underpriviliged people are extpected able to increse their income as well as able to run their business eficient and easy. While, people outside of the LKSA also can take benefit from this ukm-online, because their eficiency of time, place, and budget is also increase and that will make their life more easy and less stress.
\end{abstract}

Keywords: Websites; UKM-online; front-end; back-end; full-stack. 


\section{Pendahuluan}

Lembaga Kesejateraan Sosial Anak (LKSA) Prasejahtera merupakan lembaga sosial di bawah Yayasan Al Abrar sebuah yayasan sosial yang berlokasi di Makassar, Sulawesi Selatan. Lembaga ini adalah lembaga yang menampung para balita prasejahtera yang berdomisi di Makassar. Para balita ini merupakan anak dari keluarga yang tak mampu perekonomiannya sehingga disebut prasejahtera. Kondisi ekonomi keluarga mereka yang tak menunjang membuat tumbuh kembang mereka tidak sesuai seperti anak anak seusianya, mereka mengalami kekurangan gizi di usia balita karena kondisi ekonomi orang tua yang memprihatinkan.

Selama ini telah banyak tindakan yang diambil oleh LKSA sebagai lembaga sosial, namun hal tersebut belum mampu memenuhi kebutuhan dari para balita ini dalam bertumbuh kembang. Hal ini disebabkan jumlah balita prasejahtera di Makassar ini sangat besar sekali sementara lembaga ini hanya bergantung dari dana bantuan dari kesadaran sosial masyarakat sekitar yayasan. Sehingga lembaga ini masih kekurangan dana dalam melakukan pembinaan terhadap para orang tua dari balita prasejahtera ini.

Berdasarkan potensi dan keterampilan yang umum dimiliki masyarakat ini, bidang usaha kuliner dipilih untuk dikembangkan menjadi bisnis online yang akan dipasarkan di seluruh Indonesia.

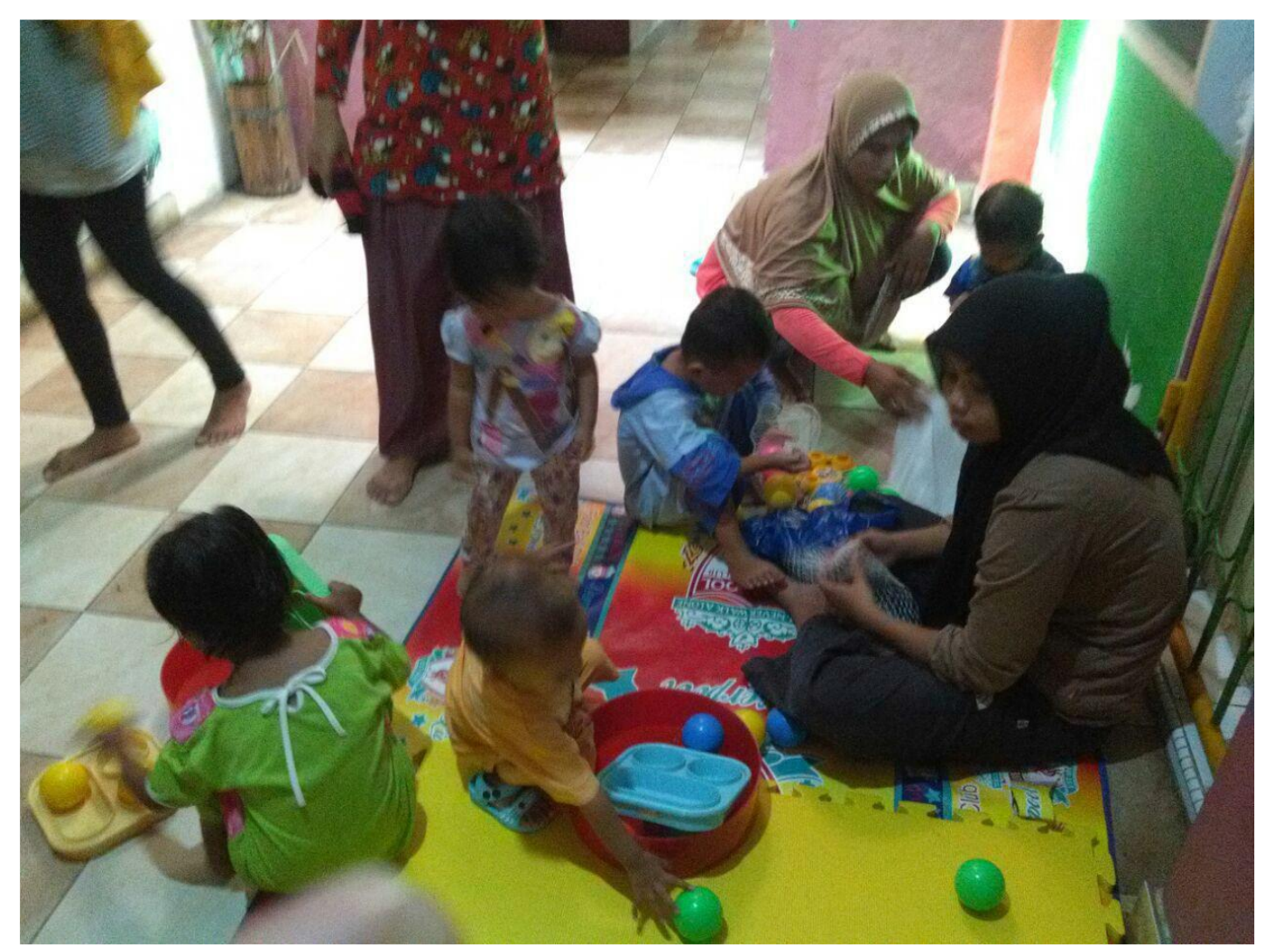

Gambar 1. Gambaran balita yang dibina LKSA Makassar 


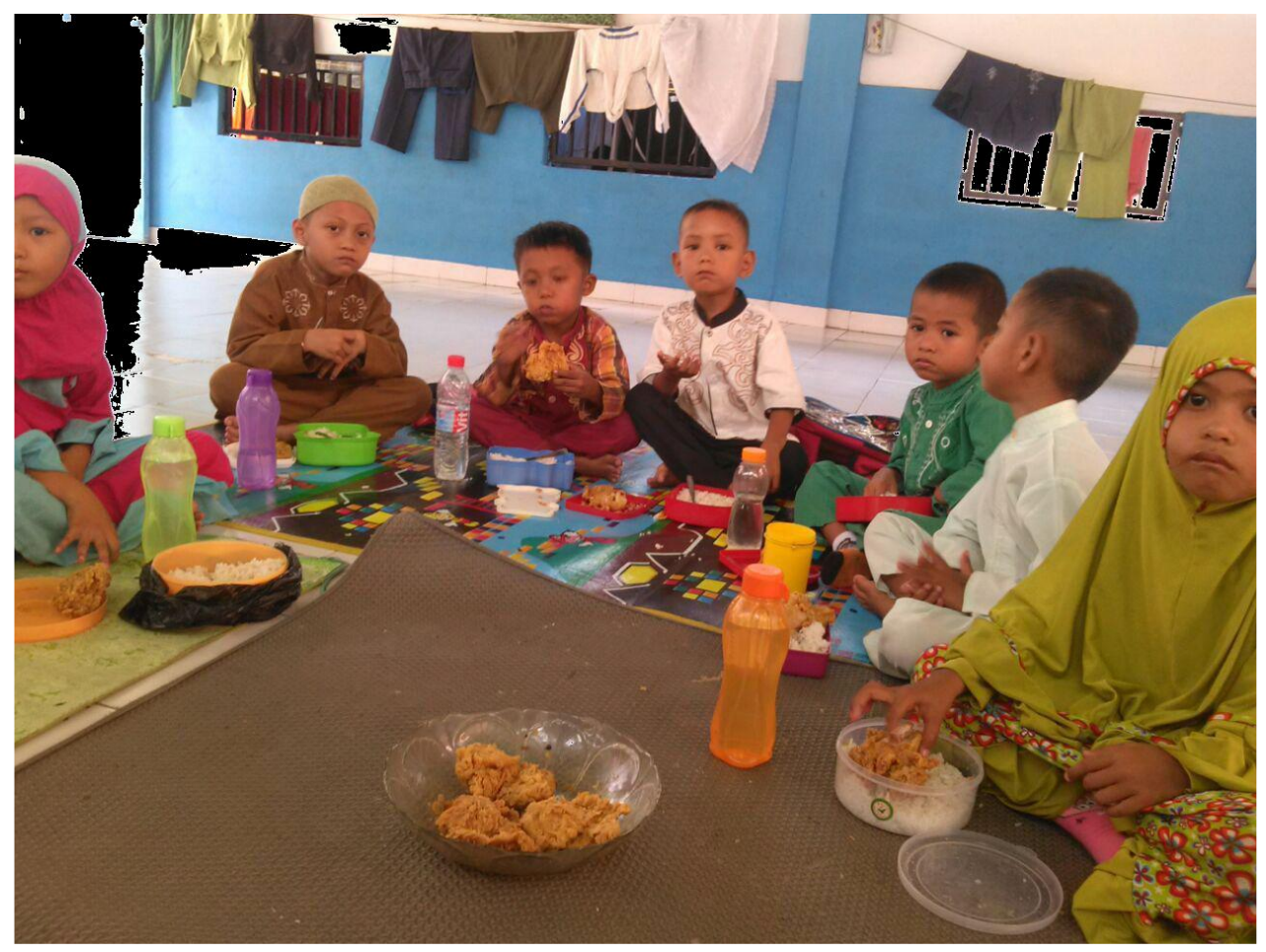

Gambar 2. Balita-balita yang tergabung dalam LKSA prasejahtera

Namun, kondisi sumber daya pada lembaga ini belum mampu untuk bekerja sesuai dengan target yang diharapkan. Beberapa pengurus lembaga telah mengerti menggunakan komputer dan internet, namun kurang memahami desain pembuatan website, optimisasi website sebagai bisnis online yang mampu menghasilkan penghasilan pasif maupun aktif, dan teknik pemasaran bisnis diinternet. Sehingga, dilakukan pelatihan pelatihan yang dibutuhkan untuk melengkapi pengurus lembaga dan ibu-ibu orang tua balita prasejahtera ini dengan keahlian yang diperlukan dalam menjalankan bisnis ini.

Lembaga ini memilki sumber daya manusia yang memiliki keahlian di bidang kesehatan dan gizi. Sehingga pemilihan produk yang tepat untuk dipasarkan dan teknik mengemas produk yang menarik untuk dipasarkan akan dilakukan sepenuhnya oleh pengurus lembaga ini. Sementara pembuatan website UKM-online dikerjakan oleh tim pengabdian Unhas.

\section{Membangun Websites untuk UKM Online}

Web developer adalah sebuah profesi yang berperan untuk mendesain websites sesuai dengan permintaan pelanggan. Web developer juga menangani data yang trsimpan dan keamanan website tersebut.

\subsection{Tipe web-developer}

(1) Front-end developer

Web developer ini bertanggung jawab untuk mengatur lay-out desain websites, memberikan style pada websites, dan mengatur segala hal yang berkaitan dengan tampilan website di layar. Bahasa pemograman yang perlu dikuasai adalah HTML, CSS, Java-script, dan CMS. 
(2) Back-end developer

Web developer ini berperan untuk membangun sistem yang mampu membuat website beroperasi. Bahasa pemograman yang perlu dikuasai adalah phyton, PHP, dan CVS.

(3) Full-stack developer

Web-developer ini menguasai keduanya yaitu front-end developer dan back-end developer.

Bahasa pemograman yang dibutuhkan untuk membangun sebuah websites, dibagi atas beberapa kategori berdasarkan jenis web developer, antara lain:

\subsection{Front-end developer}

(1) HTML (Hypertext Markup Language)

Bahasa pemograman paling dasar dalam perancangan websites, yang berfungsi untuk mengatur tampilan lay-out dari websites.

(2) CSS (Cascade Style Sheet)

CSS merupakan bahasa pemograman yang membuat isi dari website yang anda atur menjadi lebih menarik. Misalnya, memberi warna, memberi latar belakang gambar, mengatur gambar dan video, mengubah bentuk huruf, mengubah ukuran margin. memberikan efek atau animasi, dan lain-lain.

\section{(3) Javascript}

Bahasa pemograman ini mampu meningkatkan tampilan website menjadi lebih menawan. Mengembangkan isi website yang diprogram menggunakan HTML dan CSS menjadi lebih menarik dan interaktif.

(4) CMS (Content Management System)

Jenis CMS yang sering digunakan adalah wordpress dan wix. CMS menyediakan template dan frame yang memudahkan user dalam merancang website. Namun, merancang websites dengan CMS memiliki banyak batasan, sebab website terkesan kaku dan terikat pada template yang disediakan CMS, perancang websites kurang memiliki control terhadap isi dari websites, serta kurang dapat mengatur websitenya. Sehingga, seorang web developer yang bagus biasanya menggabungkan antara CMS dan hand-coding.

\subsection{Back-end developer}

\section{(1) PHP}

Bahasa pemograman yang sering digunakan di platform seperti wordpress maupun wix dan umumnya dipakai untuk merancang $80 \%$ website di seluruh dunia.

(2) Java

Bahasa pemograman yang digunakan untuk mengembangkan program yang lebih sulit seperti yang berhubungan dengan server, database, dan berbagai macam aplikasi didalam website. Java sering dipakai untuk merancang websites agar lebih responsive.

\section{Metode pembuatan website untuk UKM online}

Berdasarkan metode pemograman websites yang telah dijelaskan pada bagian teori di atas, tim pengabdian Unhas telah merancang sebuah website untuk UKM LKSA Prasejahtera dengan mengunakan teknik hand-coding. Berikut adalah tampilan awal dari website tsb. 


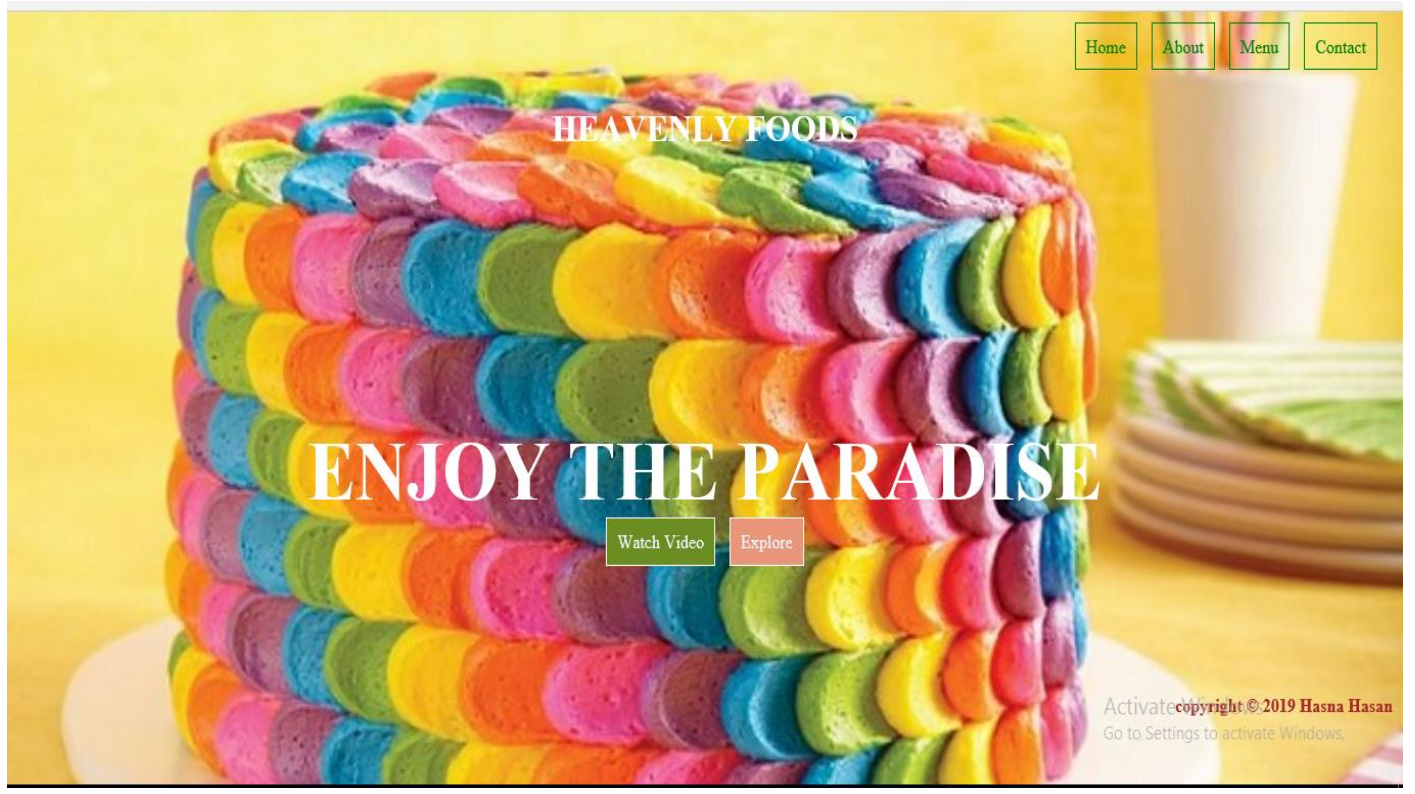

Gambar 3. Tampilan halaman awal dari websites UKM online

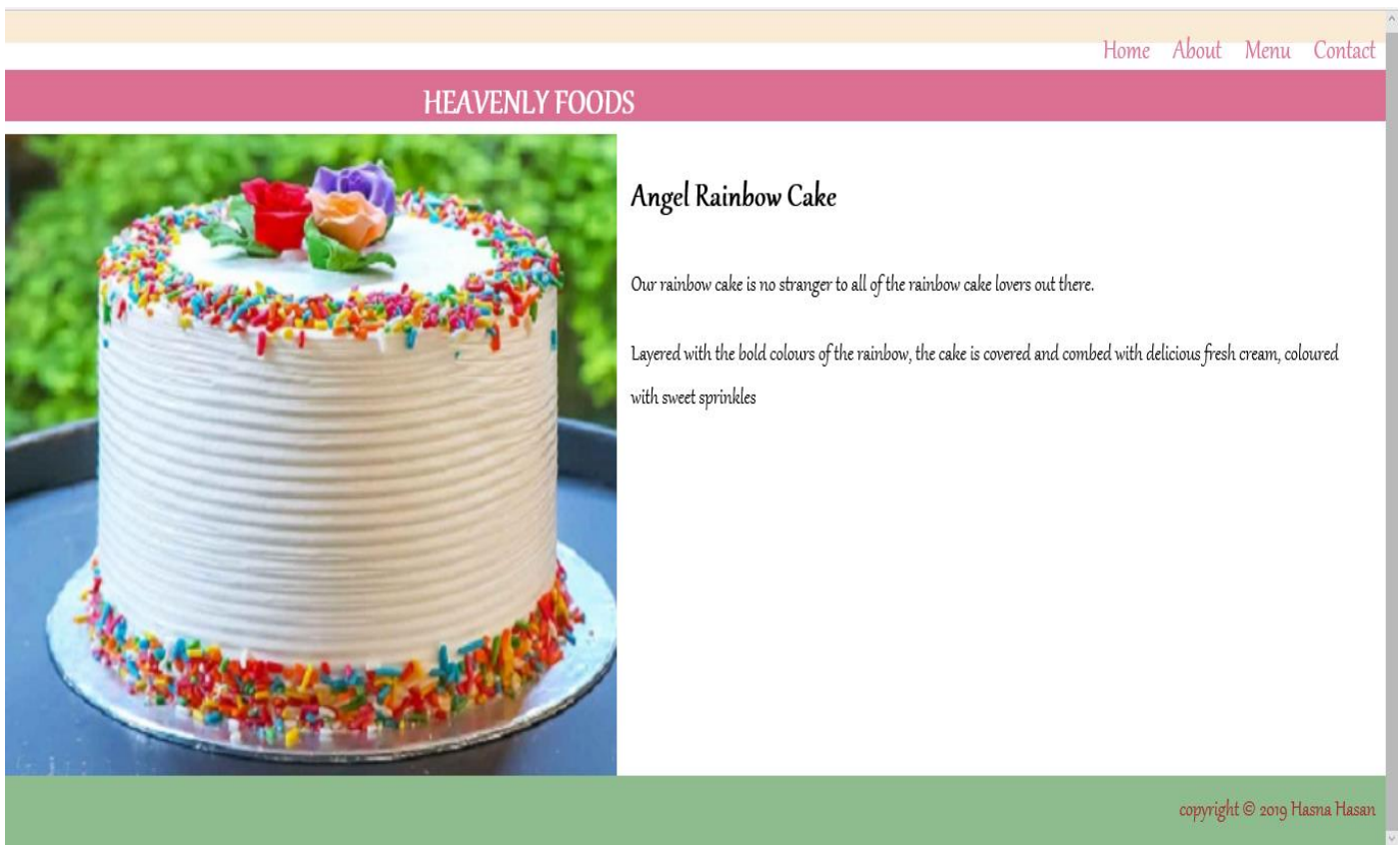

Gambar 4. Salah satu tampilan menu 


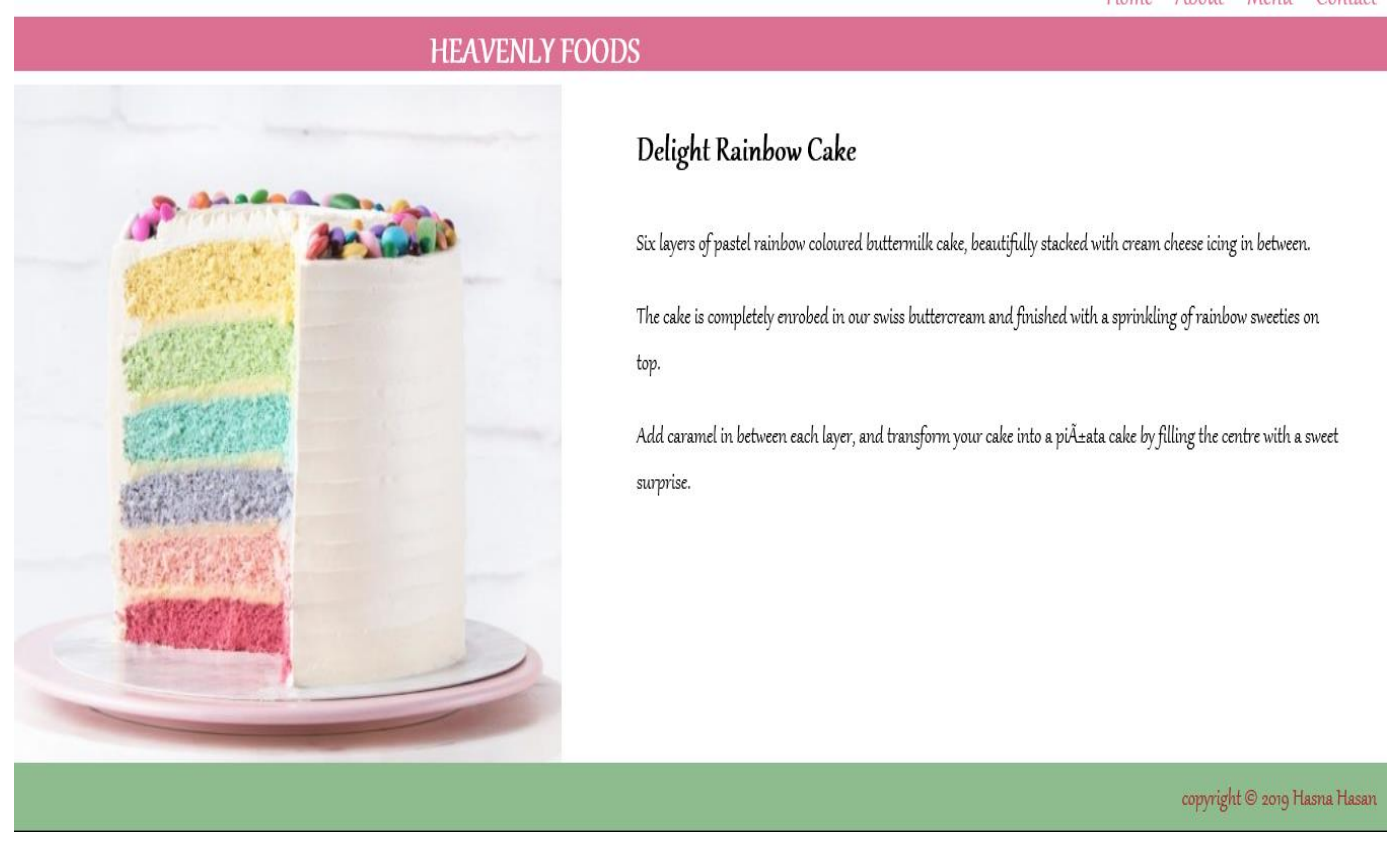

Gambar 5. Salah satu menu yang ditawarkan di dalam website UKM online ini.

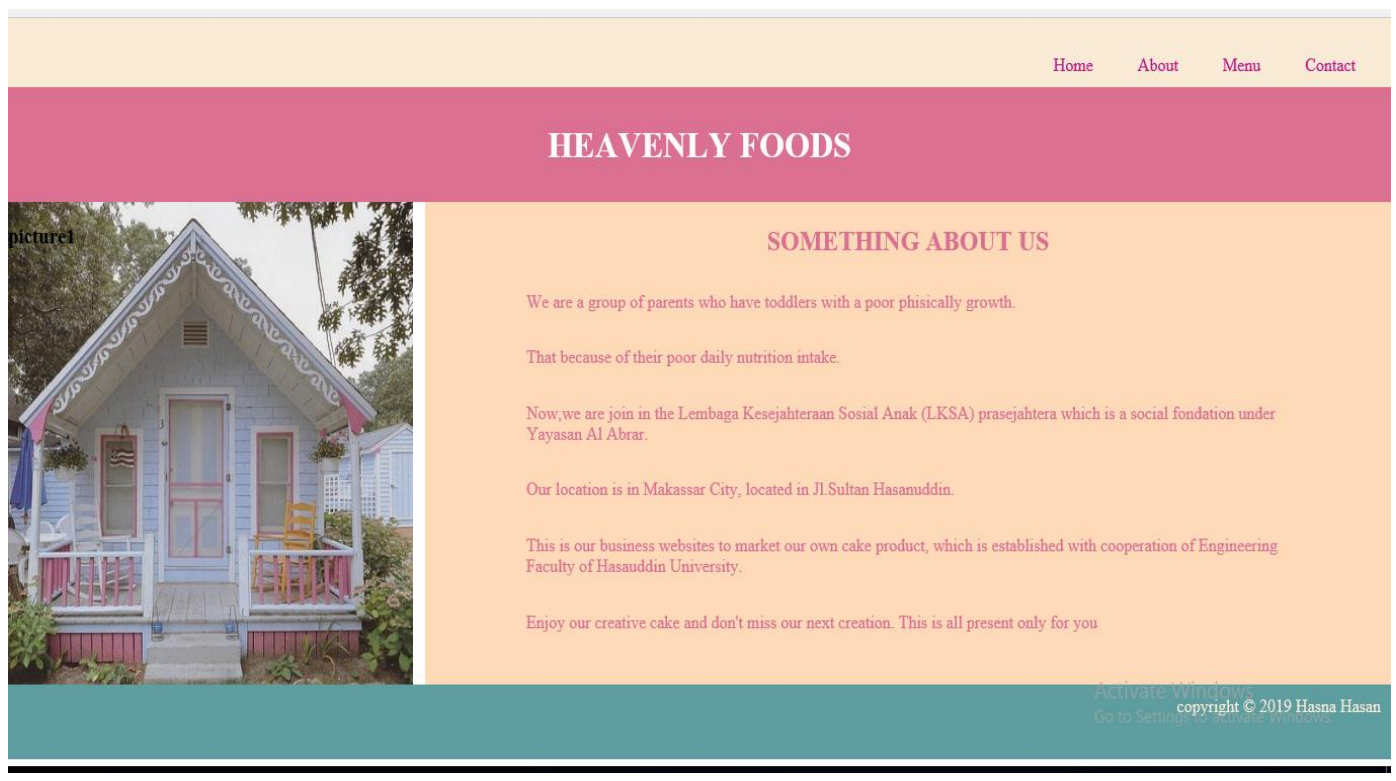

Gambar 6. Deskripsi singkat mengenai LKSA prasejahtera, pengelola UKM.

\section{Hasil dan Diskusi}

Pada jaman ini, masyarakat umum lebih sering menggunakan media online dalam kehidupan sehari hari. Sejauh ini para pengusaha kuliner telah mengenal gojek dan grab sebagai media yang mampu memasarkan produk mereka. Hanya saja gojek dan grab terbatas pada memasarkan produk tapi belum tentu menarik pelanggan. Mendesain sebuah website yang menarik, mempresentasekan produk para pengusaha dengan lebih jelas dan menarik perhatian konsumen. 
Pada website ini, terlihat produk yang mereka jual secara jelas lengkap dengan deskripsi produk dan tampilannya. Selain daripada itu profil pengusaha UKM akan terlihat dengan jelas.

Selain daripada itu, memiliki website sendiri membuat para pengusaha mampu menjangkau para konsumennya, mengetahui kekurangan yang dimiliki produk mereka, mendapatkan feedback dari masyarakat, dan mampu menawarkan produk mereka dengan jangkauan yang lebih luas.

\section{Kesimpulan dan Saran}

UKM merupakan salah satu bentuk usaha yang diharapkan oleh masyarkat prasejahtera di Indonesia. Munculnya banyak balita yang mengalami masalah gizi disebabkan oleh ekonomi keluarganya yang kurang mampu.

Pengembangan UKM yang dikelola oleh ibu-ibu dari para balita ini sering menjadi solusi bagi masalah ekonomi yang mereka hadapi. Namun, besarnya biaya sewa tempat menjual ditempat yang strategis menjadi masalah utama bagi ibu-ibu di LKSA prasejahtera ini.

Website bisa jadi sebuah solusi yang tepat untuk mengatasi masalah biaya sewa tempat usaha yang terlalu besar. Pembangunan sebuah website tidak membutuhkan biaya yang besar, cukup ratusan ribu untuk menyewa domain. Namun membangun sebuah websites membutuhkan seorang web developer untuk merancangnya. Oleh karena itu, tim pengabdian Unhas dalam program pengabdian ini merancang sebuah websites untuk UKM kecil ini agar mampu berkembang meski tak memiliki tempat untuk berjualan.

Namun diharapkan, masyarakat mengerti cara memasarkan produknya meski telah memiliki websites sendiri dan tetap konsisten dalam menjalankan usaha UKM ini agar terus berkembangan. Jika memilki website sendiri, para UKM lebih mudah memasarkan produknya via media sosial. Sehingga jaringan usaha mereka mampu berkembang dengan baik.

\section{Ucapan Terima Kasih}

Ucapan terima kasih kepada pimpinan Yayasan Al Abrar dan pimpinan yayasan LKSA (Lembaga Kesejahteraan Sosial Anak) Prasejahtera di Makassar, yang telah memfasilitasi pelaksanaan kegiatana ini serta turut serta mendorong keaktifan masyarakat dalam kegiatan ini. Penghargaan yang setinggi-tingginya kepada LP2M Unhas melalui hibah internal pengabdian kepada masyarakat pada skim PKM yang telah mampu mendukung terlaksananya kegiatan ini. Ucapan terima kasih juga kepada ibu-ibu dari para balita yang tergabung pada LKSA atas partisipasinya dalam kegiatan pengabdian ini.

\section{Daftar Pustaka}

Oviliana Y Yuliana, (2000). Penggunaan Teknologi Internet dalam Berbisnis, Jurnal Akuntansi dan Keuangan.

Peter Kent \& Jill.K,F, (2014). How To Make Money Online, Mc.Graw Hill.

Sukarto dan Hionoto, (2009). Sukses Berbisnis dalam 29 Hari, PT.Gramedia.

Tonya B, (2009). How To Start an Ebay Store The Right Way The First Time, Tonya Dynamic Design. 